IP Periodica Polytechnica Chemical Engineering

62(1), pp. 43-50, 2018

https://doi.org/10.3311/PPch.9741

Creative Commons Attribution (i)

RESEARCH ARTICLE

\section{The Investigation of Effects of Temperature and Nanoparticles Volume Fraction on the Viscosity of Copper Oxide-ethylene Glycol Nanofluids}

\author{
Mohammad Hemmat Esfe ${ }^{1 *}$
}

Received 14 July 2016; accepted after revision 12 November 2016

\begin{abstract}
In the present article, the effects of temperature and nanoparticles volume fraction on the viscosity of copper oxide-ethylene glycol nanofluid have been investigated experimentally. The experiments have been conducted in volume fractions of 0 to $1.5 \%$ and temperatures from 27.5 to $50{ }^{\circ} \mathrm{C}$. The shear stress computed by experimental values of viscosity and shear rate for volume fraction of $1 \%$ and in different temperatures show that this nanofluid has Newtonian behaviour. The experimental results reveal that in a given volume fraction when temperature increases, viscosity decreases, but relative viscosity varies. Also, in a specific temperature, nanofluid viscosity and relative viscosity increase when volume fraction increases. The maximum amount of increase in relative viscosity is $82.46 \%$ that occurs in volume fraction of $1.5 \%$ and temperature of $50{ }^{\circ} \mathrm{C}$. Some models of computing nanofluid viscosity have been suggested. The greatest difference between the results obtained from these models and experimental results was down of 4 percent that shows that there is a very good agreement between experimental results and the results obtained from these models.
\end{abstract}

\section{Keywords}

dynamic viscosity, nanofluid, solid volume fraction, ethylene glycol

\section{Introduction}

Ethylene glycol is an organic combination that is used in thermal transformers, automobiles, air conditioners, and cooling systems operating in a temperature lower than water freezing point. This substance has a low thermal conductivity, so a lot of efforts have been made to increase its thermal conductivity. One way to do this is to add nanoparticles to this liquid [1-6]. However, when nanoparticles are added to the fluid to increase its thermal conductivity, the other thermophysical properties of the fluid change as well [7-10]. One of the properties that is likely to change with nanoparticles addition is viscosity. Therefore, changes in viscosity due to nanoparticles addition must be investigated in order to determine the pumping power and entropy generation in nanofluid flow in order to optimize the various devices [11]. In previous researches, the effect of adding different nanoparticles to ethylene glycol has been studied such as $\mathrm{A} 12 \mathrm{O} 3$ nanoparticles $[12,13], \mathrm{ZnO}$ [14], and UDD (Ultra Dispersed Diamond) [15]. One of the nanoparticles used in different researches is copper oxide [1621]. Some researchers have been conducted on $\mathrm{CuO} / \mathrm{EG}$ nanofluid so far. Liu et al. [22] investigated this nanofluid relative thermal conductivity for different volume fractions of copper oxide nanoparticles. Zhu et al. [23] experimented specific thermal capacity for different volume fractions and suggested a model for the obtained experimental data. Quack and Kim [24] investigated the variations in zero shear viscosity for different volume fractions and compared the obtained results with present models. They also studied the way nanofluid viscosity changes with different shear rates for nanofluid various volume fractions. However, in none of these researches the effect of temperature variations on viscosity and shear rate of $\mathrm{CuO} / \mathrm{EG}$ nanofluid has been investigated. The measurement of variations of nanofluid viscosity for different temperatures was first conducted by Masuda et al. [25] and continued by other researchers subsequently. Some researchers in their works reported that nanofluid relative viscosity increased with an increase in temperature [26]. In some other researches, a decrease in relative viscosity has been reported [27].

\footnotetext{
${ }^{1}$ Department of Mechanical Engineering, Imam Hossein University, Tehran, Iran

*Corresponding author, e-mail: M.hemmatesfe@semnan.ac.ir
} 
The rheological behaviour of EG affected by nanoparticles can be complicated. In Pastoriza-Gallego et al. [28, 29] study, the Newtonian behaviour of $\mathrm{Al} 2 \mathrm{O} / \mathrm{EG}$ and $\mathrm{ZnO} / \mathrm{EG}$ was obvious. Also, Żyła [30] and Mariano et al. [31] investigated the viscosity of $\mathrm{Y} 3 \mathrm{~A} 15 \mathrm{O} 12 / \mathrm{EG}$ and Co3O4/EG, respectively. Their results indicated that their nanofluids were Newtonian. On the other hand, some researchers such as Żyła et al. [32, 33], Li et al. [35], Mariano et al. [34] and Li et al. [35] observed
non-Newtonian behaviour of A12O3, AlN, SnO2, SiC nanoparticles dispersed in ethylene glycol.

In the present article, the effect of temperature variation and volume fraction on viscosity of $\mathrm{Cuo} / \mathrm{FG}$ nanofluid has been investigated and a relationship has been presented for it.

In the Table 1, a summary of relationships suggested for viscosity variation of different nanofluids due to temperature variation has been presented.

Table 1 Research on modelling the properties of nanofluids

\begin{tabular}{|c|c|c|c|}
\hline Authors & Base fluid & Dispersed particles & Correlation \\
\hline Hemmat et al. [13] & EG & $\mathrm{ZnO}$ & $\frac{\mu_{n f}}{\mu_{b f}}=0.9118 \exp \left(5.49 \varphi-0.00001359 T^{2}\right)+0.0303 \ln (T)$ \\
\hline Nguyen et al. [24] & water & $\mathrm{Al}_{2} \mathrm{O}_{3}$ & $\begin{array}{l}\text { For } \varphi=1 \% \\
\frac{\mu_{\mathrm{nf}}}{\mu_{\mathrm{bf}}}=1.125-0.0007 \mathrm{~T} \\
\text { For } \varphi=1 \% \\
\frac{\mu_{\mathrm{nf}}}{\mu_{\mathrm{bf}}}=2.1275-0.0215 \mathrm{~T}+0.0002 \mathrm{~T}^{2}\end{array}$ \\
\hline Jamshidi et al. [25] & EG/water & $\mathrm{SiO}_{2}$ & $\begin{array}{l}\mu_{\mathrm{nf}}=\operatorname{Exp}(\mathrm{aT}+\mathrm{b}) \\
\mathrm{a}=-0.03959-0.01523 \varphi \\
\mathrm{b}=3.53267+6.3848 \varphi\end{array}$ \\
\hline
\end{tabular}

$\begin{array}{ll} & \ln \left(\mu_{\mathrm{nf}}\right)=\mathrm{A}\left(\frac{1}{\mathrm{~T}}\right)-\mathrm{B} \\ \text { Kulkarni et al. [26] water } \quad \mathrm{CuO} & \mathrm{A}=20587 \varphi^{2}+15857 \varphi+1078.3 \\ & \mathrm{~B}=-107.12 \varphi^{2}+53.548 \varphi+2.8715\end{array}$

\begin{tabular}{lll}
\hline & & $\log \left(\mu_{\mathrm{nf}}\right)=\mathrm{Ae}^{-\mathrm{BT}}$ \\
Namburu et al. [16] EG/water $\quad \mathrm{CuO}$ & $\mathrm{A}=1.8375 \varphi^{2}-29.643 \varphi+165.56$ \\
& & $\mathrm{~B}=4 \times 10^{-6} \varphi^{2}-0.001 \varphi+0.0186$
\end{tabular}

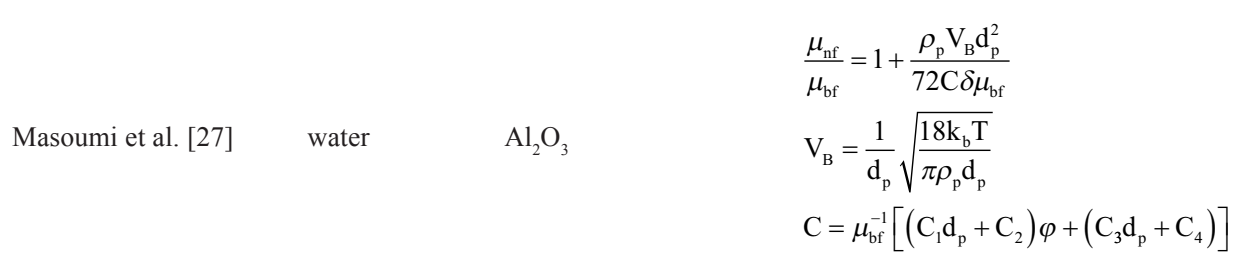

$\begin{array}{ll} & \frac{\mu_{\mathrm{nf}}}{\mu_{\mathrm{bf}}}=\left(1+308.7 \varphi+0.9649 \varphi^{3}\right) \times \\ & \\ \text { Singh et al. [28] } \quad\left(1-20.55 \exp \left(-36.94 \mathrm{~T}_{\mathrm{r}}+137.7 \mathrm{~T}_{\mathrm{r}}^{-1}-108.6 \mathrm{~T}_{\mathrm{r}}^{-2}\right)\right) \\ & \mathrm{T}_{\mathrm{r}}=\frac{\mathrm{T}}{298}\end{array}$




\section{Experimental}

\subsection{Dynamic viscosity measurement}

In current study the viscosity of the $\mathrm{CuO}-$ Ethylene glycol was measured by Brookfield viscometer equipped with a temperature bath. Referred apparatus enable us to adjust the temperature at every proposed value. It is worth to note that the accuracy of measured value is $\pm 1.0 \%$ with $\pm 0.2 \%$ repeatability. Before using the viscometer it regulate by using the glycerine and ethylene glycol at room temperature. Every test was repeated more than two times for each volume fraction to assure its repeatability, and then the average values was recorded.

\subsection{CuO-ethylene glycol nanofluids preparation}

In this investigation two-step method was used method for preparing of nanofluids. In refereed method, in first step the nanoparticles are synthesized, followed by their dispersion in base fluid as the second step. In addition, probe ultra-sonication, Surfactants, high-shear mixing and stirring are also used in order to reach to the acceptable nanoparticle dispersion. As it is well known amount of used surfactant, and applying time of ultra-sonication and mixing time can influence strongly the properties and stability of nanofluids. $\mathrm{CuO}$-ethylene glycol nanofluid was prepared with very low concentration of surfactant-less. In this work $\mathrm{CuO}$ nanoparticles with average diameter of $40 \mathrm{~nm}$ were dispersed in ethylene glycol using shear homogenization and probe ultra-sonication $(1200 \mathrm{~W}, 20 \mathrm{kHz}$, Kimia nano danesh). For each volume fraction required $\mathrm{CuO}$ nanopowder was added to ethylene glycol and exposed to shear homogenization for $15 \mathrm{~min}$ at low speeds and followed by higher speeds. The sample was then ultrasonicated using a probe ultrasonicator $(1200 \mathrm{~W}, 20 \mathrm{kHz}$, Kimia nano danesh). In order to obtain the optimum ultra-sonication time the thermal conductivity and viscosity at different time periods were measured. For preparing the lower nanofluids concentration the $\mathrm{CuO}-$ ethylene glycol nanofluid was diluted.

\section{Results and discussion}

\subsection{Comparison between the results obtained from theoretical models and experimental results}

In Fig. 1, a comparison of the results obtained from theoretical models (Einstein [41], Wang et al. [12] and Batchelor [42]) and experimental results has been shown. As is evident, there is a big difference between experimental results and the results obtained from these models, and these models are not able to estimate the viscosity of copper oxide-ethylene glycol nanofluid.

\subsection{Newtonian behaviour}

It should be initially recognized if copper oxide-ethylene glycol nanofluid has Newtonian or non-Newtonian behaviour. For this purpose, the following relationship can be used which shows Newtonian fluid behaviour.

$$
\tau=\mu \frac{\partial u}{\partial y}=\mu \gamma
$$

In this relationship, $\tau$ is shear stress, $\mathrm{M}$ is dynamic viscosity, and $\Upsilon$ is shear rate. According to this relationship, when shear stress has a linear relationship with shear rate, the fluid is Newtonian. Figure 2 shows variations in shear stress in terms of shear rate for volume fraction of $1 \%$ and in different temperatures. It is evident in this figure that copper oxide-ethylene glycol nanofluid with volume fraction of $1 \%$ and in different temperatures has a Newtonian behaviour.

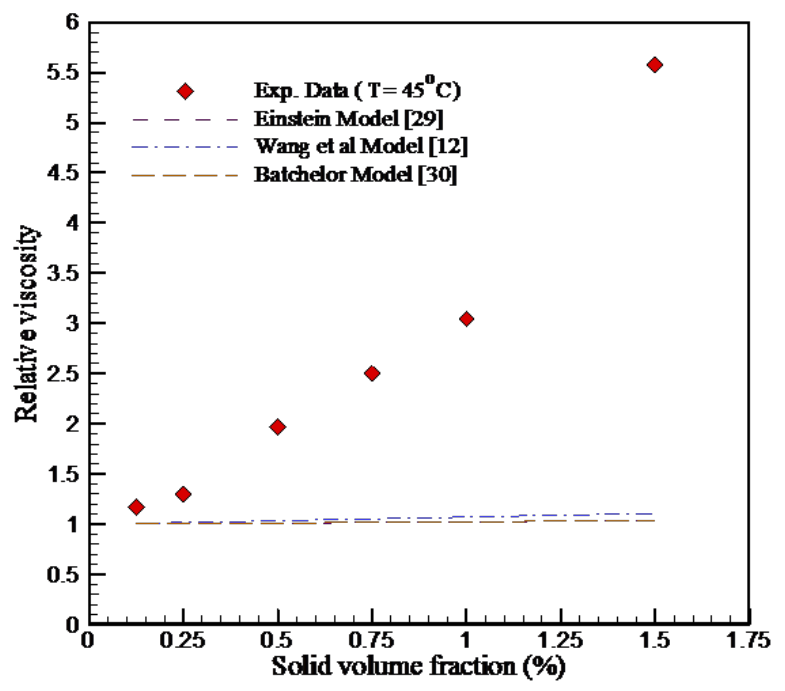

Fig. 1 The comparison between experimental data and the results obtained from theoretical models

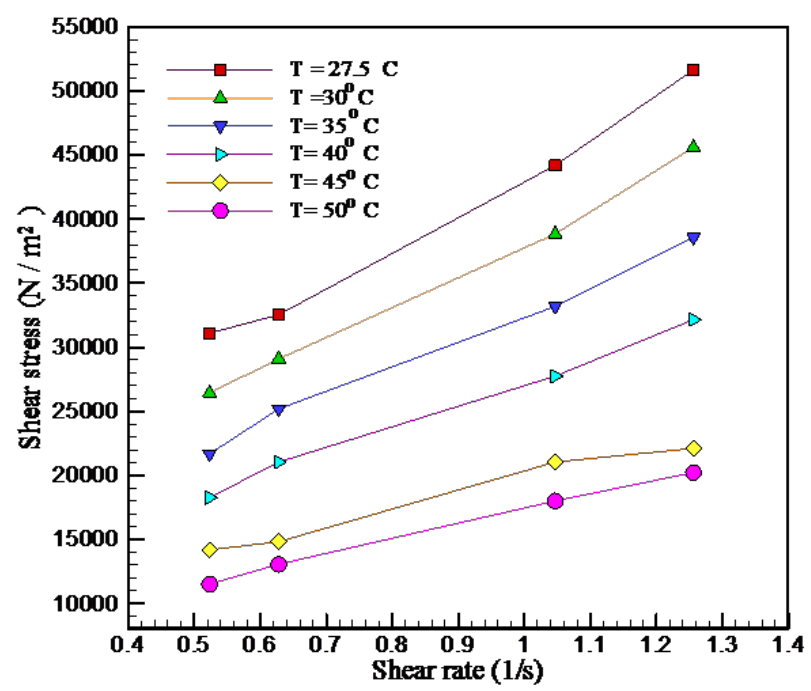

Fig. 2 Shear stress in terms of shear rate for copper oxide-water nanofluid with volume fraction of $1 \%$ in different temperatures 


\subsection{The effect of volume fraction and temperature on dynamic viscosity}

In Fig. 3, the variations of dynamic viscosity in terms of volume fraction in different temperatures have been shown. From this figure, one can realize that nanofluid viscosity increases with an increase in nanofluid volume fraction in all investigated temperatures. Also, variations of viscosity in a given volume fraction in lower temperatures are greater compared to higher temperatures. In addition, in a volume fraction, viscosity decreases when temperature increases.

With adding nanoparticles into base fluid, internal shear stress increases. In the other words, when solid volume fraction is increased, fluid resistance against the movement rises and then it is expected that the dynamic viscosity is increased.

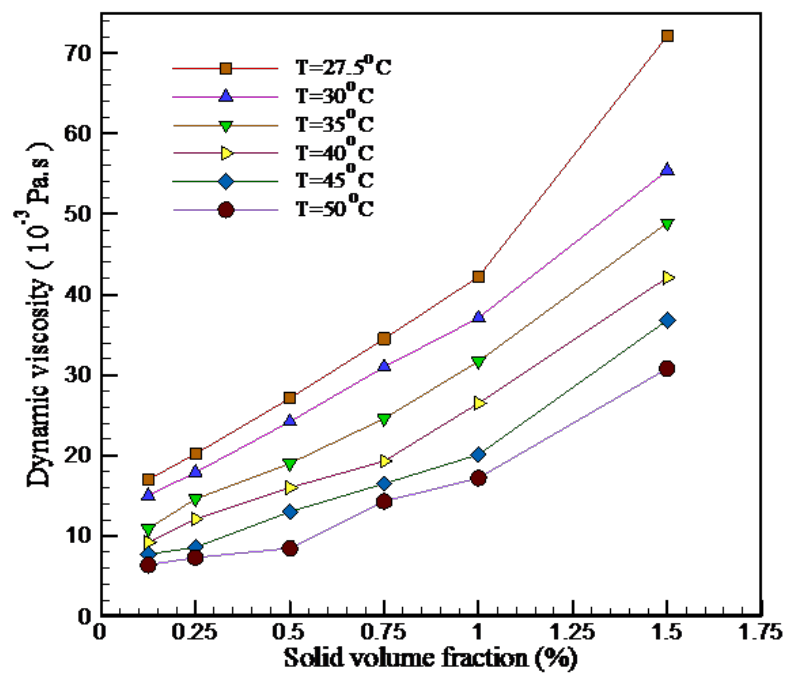

Fig. 3 Variations of viscosity in terms of volume fraction in different temperatures

Figure 4 shows the effect of temperature on viscosity in different volume fractions. According to this figure, in each volume fraction, viscosity decreases with an increase in temperature, and in a given temperature, viscosity increases when volume fraction increases. Due to increase temperature, the motion of particles in nano oil will be more intense and the molecular force will be reduced. Therefore, fluid becomes easier to move. Hence, it is expected that an increase in temperature, reduce viscosity.

Figures 5 and 6 show the proportion of nanofluid viscosity to base fluid viscosity in terms of nanoparticles volume fraction and temperature, respectively. It is observed that the greatest and smallest increase in proportion of nanofluid viscosity to base fluid viscosity were $82.46 \%$ and $10.58 \%$ that occurred in volume fraction and temperature of $1.5 \%, 50{ }^{\circ} \mathrm{C}$, and $0.125 \%$, $27.5^{\circ} \mathrm{C}$, respectively.

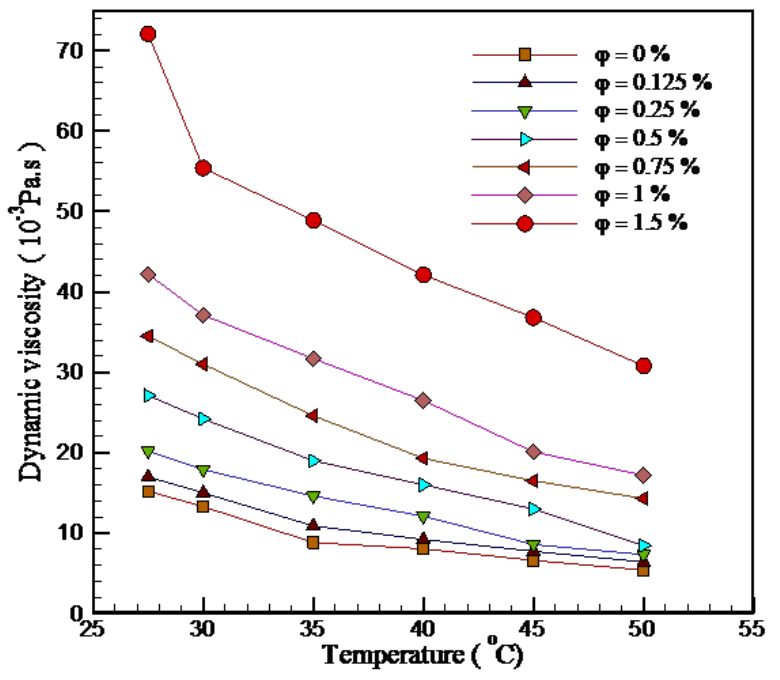

Fig. 4 Variations of viscosity in terms of temperature in different volume fractions

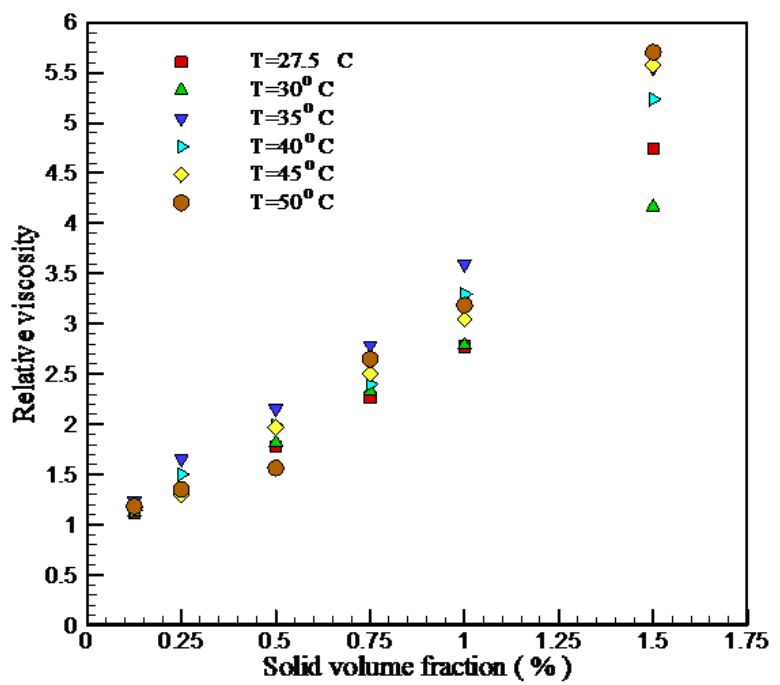

Fig. 5 Variations of relative viscosity in terms of volume fraction in different temperatures

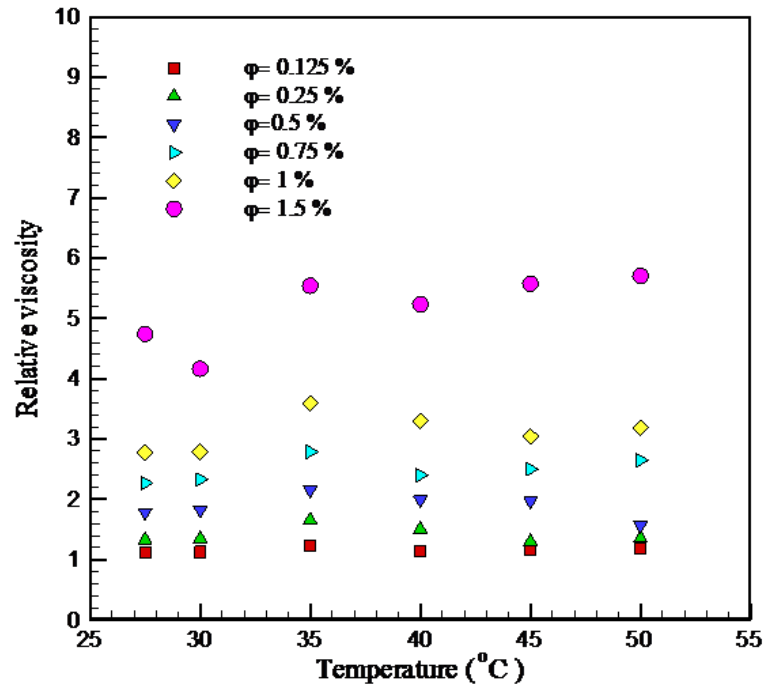

Fig. 6 Variations of relative viscosity in terms of temperature in different volume fractions 
In a given temperature, relative viscosity increases when nanoparticles volume fraction increases, but in a given volume fraction, relative viscosity fluctuates when temperature increases.

\subsection{The proposed viscosity model}

Some models in terms of nanoparticles volume fraction have been proposed to compute viscosity of copper oxide-ethylene glycol nanofluid in tested temperatures. From these models, the viscosity of copper oxide-ethylene glycol nanofluid can be obtained separately in each temperature. These models are generally expressed in the following way.

$$
\frac{\mu_{n f}}{\mu_{b f}}=a_{0}+a_{1} \varphi+a_{2} \varphi^{2}+a_{3} \varphi^{3}+a_{4} \varphi^{4}
$$

Where $\mathrm{M}$ is dynamic viscosity and $\phi$ is nanoparticles volume fraction in terms of \%. The coefficients available in this relationship in different temperatures have been presented in Table 2.

Table 2 The coefficients of the proposed viscosity model in different temperatures

\begin{tabular}{llllll}
\hline $\mathrm{T}\left({ }^{\circ} \mathrm{C}\right)$ & $\mathrm{a}_{0}$ & $\mathrm{a}_{1}$ & $\mathrm{a}_{2}$ & $\mathrm{a}_{3}$ & $\mathrm{a}_{4}$ \\
\hline 27.5 & 0.9706 & 0.9047 & 2.767 & -3.334 & 1.470 \\
30 & 0.9876 & 0.8065 & 3.148 & -3.418 & 1.268 \\
35 & 0.6737 & 5.537 & -8.844 & 8.948 & -2.713 \\
40 & 0.4294 & 7.226 & -14.65 & 14.88 & -4.600 \\
45 & 1.210 & -1.581 & 10.95 & -12.03 & 4.481 \\
50 & 1.633 & -4.958 & 16.50 & -14.63 & 4.695 \\
\hline
\end{tabular}

In order to examine the accuracy of the proposed models, the difference between experimental values of relative viscosity and the values obtained from these models has been computed from the following relationship and in Fig. 7 these differences have been shown in terms of volume fraction.

As this figure shows, the greatest amount of difference has been 4 percent and there is a very good agreement between experimental results and the results obtained from these models. Also, in Fig. 8, an agreement is observed between experimental results and the results obtained from these relationships [43]:

$$
\operatorname{Dev}=\left[\frac{\left(\frac{\mu_{n f}}{\mu_{b f}}\right)_{E x p}-\left(\frac{\mu_{n f}}{\mu_{b f}}\right)_{p r e d}}{\left(\frac{\mu_{n f}}{\mu_{b f}}\right)_{p r e d}}\right]
$$

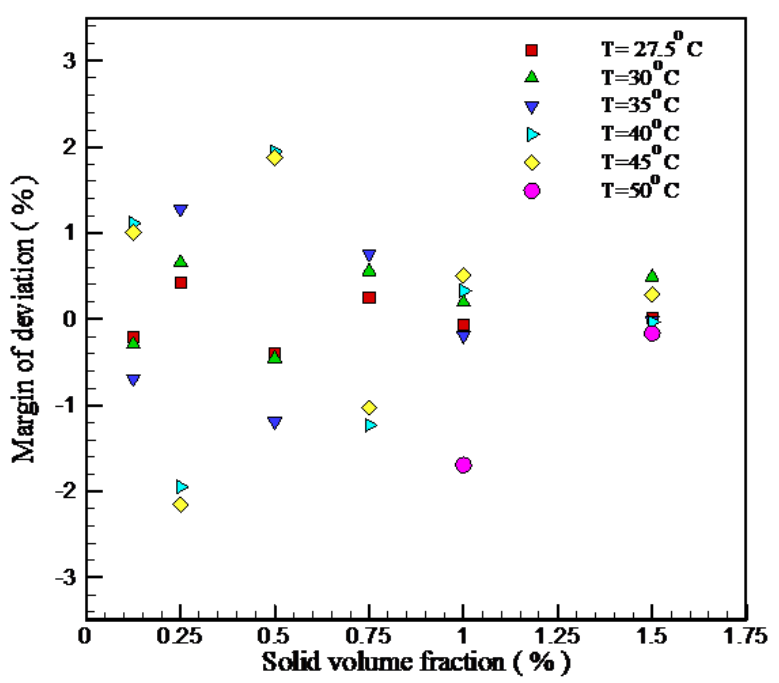

Fig. 7 Deviation of data obtained from the proposed models with experimental data

\section{Conclusions}

In the present research, dynamic viscosity of copper oxideethylene glycol nanofluid in temperatures from 27.5 to $50{ }^{\circ} \mathrm{C}$ and volume fractions of $0.125,0.25,0.5$, and $1.5 \%$ has been measured experimentally. In this research, nanofluid behaviour (nanofluid being Newtonian or non-Newtonian) and effects of temperature and volume fraction on dynamic viscosity and relative viscosity have been investigated. The obtained results can be expressed in the following way:

1. The obtained values of shear stress for volume fraction of $1 \%$ and in different temperatures through experimental values of viscosity and shear rate show that this nanofluid has Newtonian behaviour.

2. The experimental results show that in a given volume fraction with an increase in temperature, viscosity deceases, but relative viscosity varies.

3. In a given temperature, nanofluid viscosity and relative viscosity increase when volume fraction increases. The greatest amount of increase in relative viscosity has been $82.46 \%$ that has occurred in volume fraction of $1.5 \%$ and temperature of $50^{\circ} \mathrm{C}$.

4. Some models have been proposed to compute nanofluid viscosity. The maximum difference between the results obtained from these models and experimental results has been 4 percent. It shows that there is a very good agreement between experimental results and the results obtained from these models. 


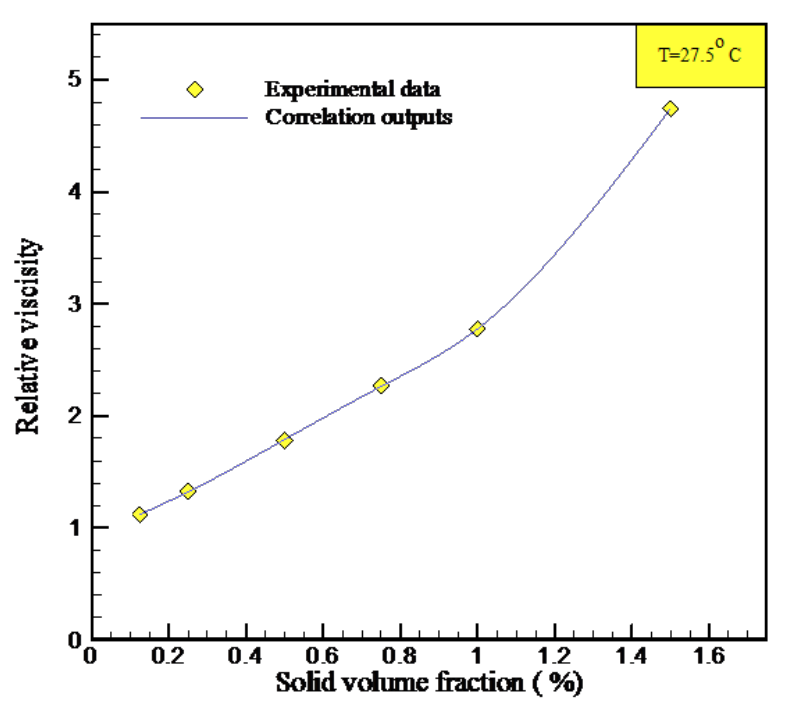

(a)

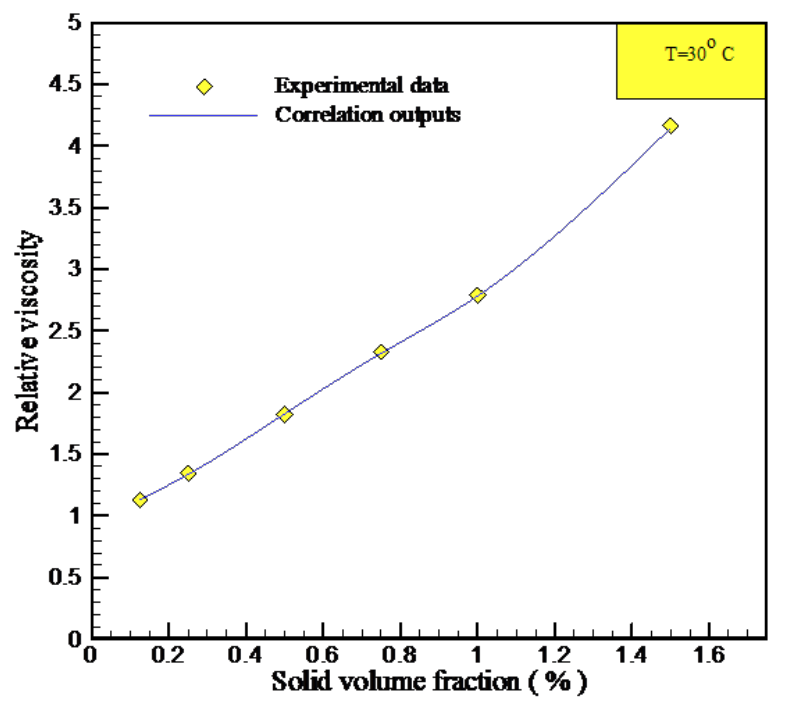

(b)

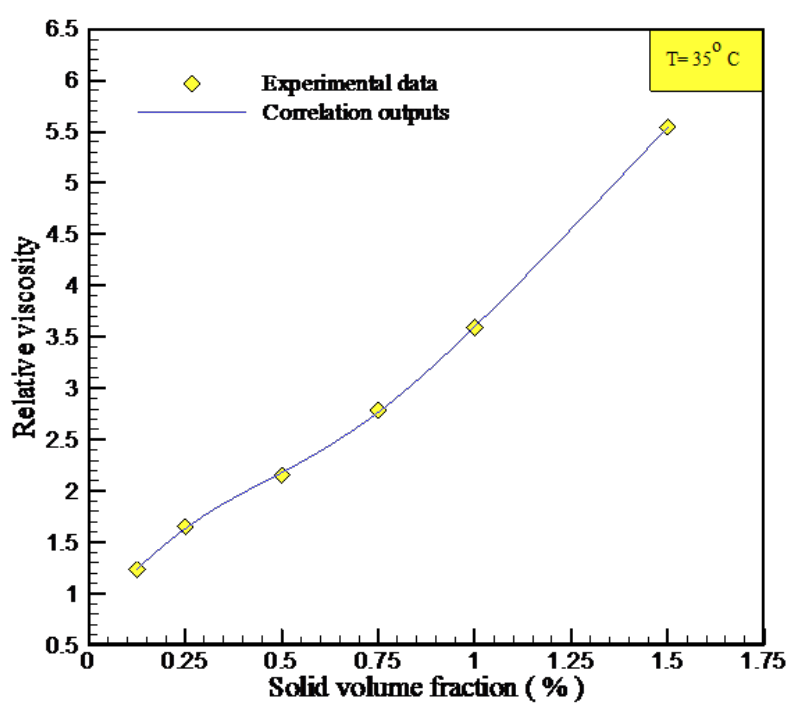

(c)

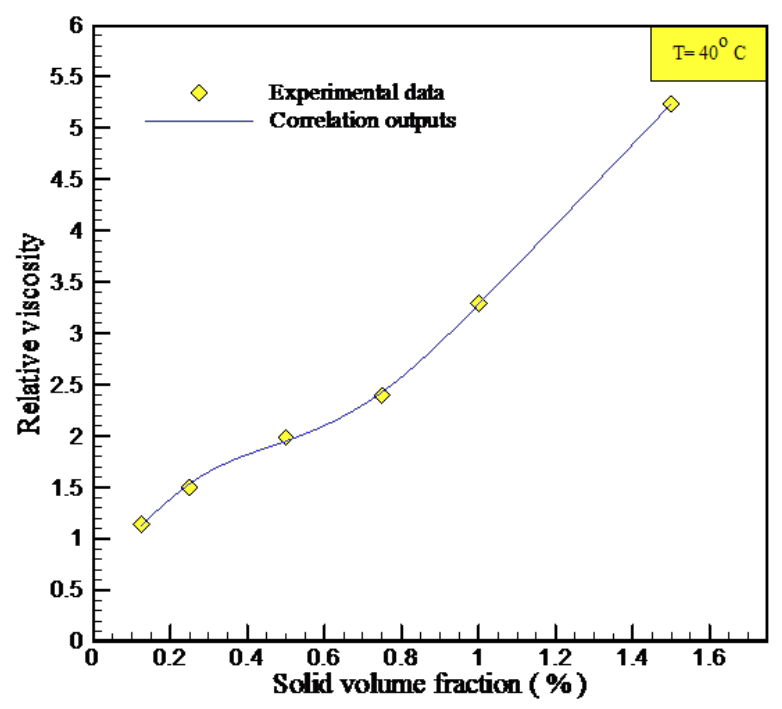

(d)

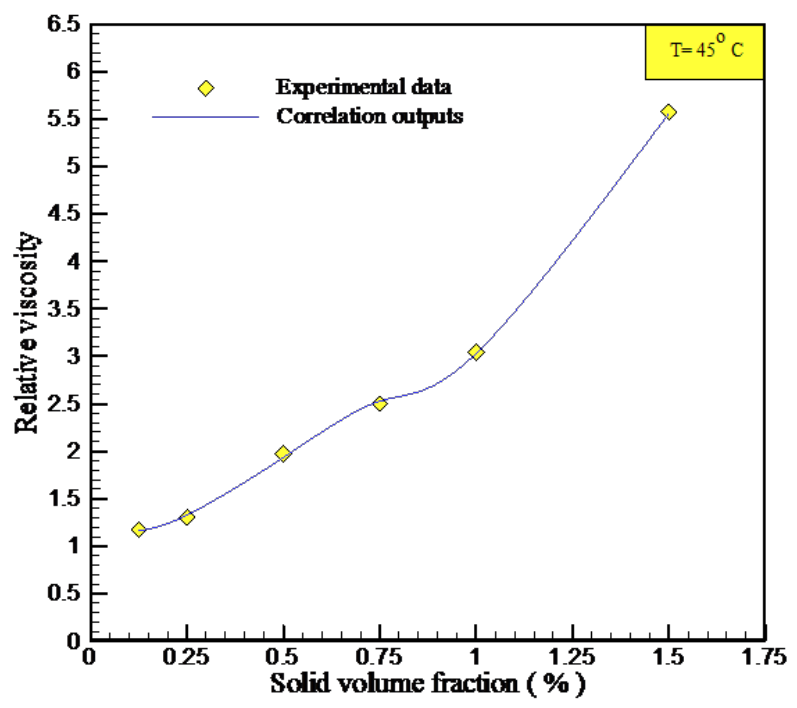

(e)

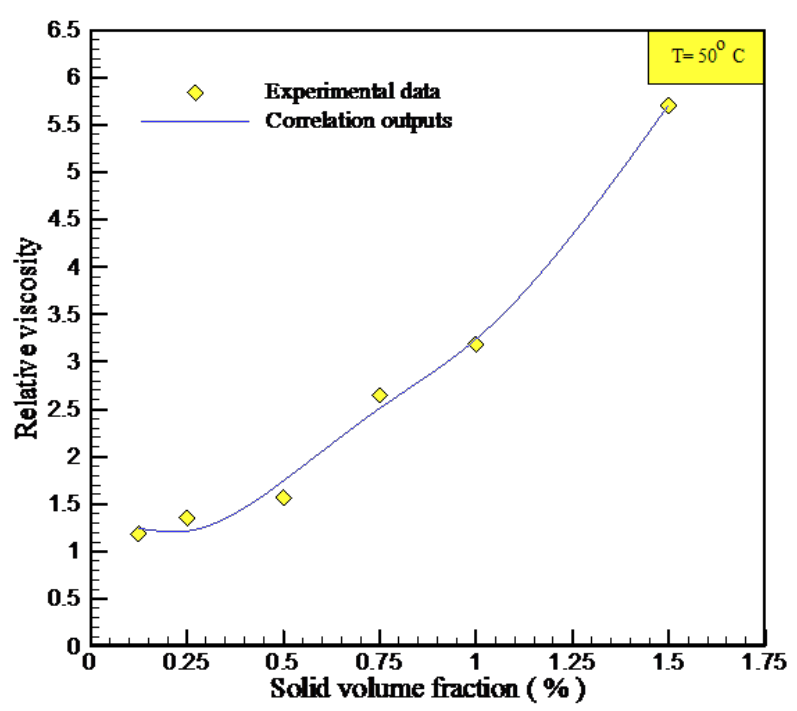

(f)

Fig. 8 A comparison between experimental data and the proposed models in (a) $\mathrm{T}=27.5^{\circ} \mathrm{C}(\mathrm{b}) \mathrm{T}=30{ }^{\circ} \mathrm{C}(\mathrm{c}) \mathrm{T}=350 \mathrm{C}(\mathrm{d}) \mathrm{T}=40{ }^{\circ} \mathrm{C}(\mathrm{e}) \mathrm{T}=45{ }^{\circ} \mathrm{C}(\mathrm{f}) \mathrm{T}=50{ }^{\circ} \mathrm{C}$ 


\section{References}

[1] Sundar, L.S., Singh, M. K., Sousa, A. C. M. "Enhanced heat transfer and friction factor of MWCNT-Fe3O4/water hybrid nanofluids." International Communications in Heat and Mass Transfer. 52, pp. 73-83. 2014. https://doi.org/10.1016/j.icheatmasstransfer.2014.01.012

[2] Hemmat Esfe, M., Afrand, M., Yan, W-M., Akbari, M. "Applicability of artificial neural network and nonlinear regression to predict thermal conductivity modeling of $\mathrm{Al} 2 \mathrm{O} 3$-water nanofluids using experimental data." International Communications in Heat and Mass Transfer. 66, pp. 246-249. 2015.

https://doi.org/10.1016/j.icheatmasstransfer.2015.06.002

[3] Hemmat Esfe, M., Afrand, M., Wongwises, S., Naderi, A., Asadi, A., Rostami, S., Akbari, M. "Applications of feedforward multilayer perceptron artificial neural networks and empirical correlation for prediction of thermal conductivity of $\mathrm{Mg}(\mathrm{OH}) 2-\mathrm{EG}$ using experimental data." International Communications in Heat and Mass Transfer. 67, pp. 46-50. 2015. https://doi.org/10.1016/j.icheatmasstransfer.2015.06.015

[4] Hemmat Esfe, M., Naderi, A., Akbari, M., Afrand, M., Karimipour, A. "Evaluation of thermal conductivity of $\mathrm{COOH}$-functionalized MWCNTs/water via temperature and solid volume fraction by using experimental data and ANN methods." International Communications in Heat and Mass Transfer. 121, pp. 1273-1278. 2015.

https://oi.org/10.1007/s10973-015-4565-5

[5] Bahrami, M., Akbari, M., Karimipour, A., Afrand, M. "An experimental study on rheological behavior of hybrid nanofluids made of iron and copper oxide in a binary mixture of water and ethylene glycol: Non-Newtonian behavior." Experimental Thermal and Fluid Science. 79, pp. 231-237. 2016. https://doi.org/10.1016/j.expthermflusci.2016.07.015

[6] Hemmat Esfe, M., Afrand, M., Karimipour, A., Yan, W.-M., Sina, N. "An experimental study on thermal conductivity of $\mathrm{MgO}$ nanoparticles suspended in a binary mixture of water and ethylene glycol." International Communications in Heat and Mass Transfer. 67, pp. 173-175. 2015. https://doi.org/10.1016/j.icheatmasstransfer.2015.07.009

[7] Hemmat Esfe, M., Akbari, M., Semiromi, D. T., Karimiopour, A., Afrand, M. "Effect of nanofluid variable properties on mixed convection flow and heat transfer in an inclined two-sided lid-driven cavity with sinusoidal heating on sidewalls." Heat Transfer Research. 45(5), pp. 409-432. 2014. https://doi.org/10.1615/HeatTransRes.2013007127

[8] Shamshirband, S., Malvandi, A, Karimipour, A., Goodarzi, M., Afrand, M., Petković, D., Dahari, M., Mahmoodian, N. "Performance investigation of micro-and nano-sized particle erosion in a 90 elbow using an ANFIS model." Powder Technology. 284, pp. 336-343. 2015.

https://doi.org/10.1016/j.powtec.2015.06.073

[9] Hemmat Esfe, M., Akbari, M., Karimipour, A., Afrand, M., Mahian, O., Wongwises, S. "Mixed-convection flow and heat transfer in an inclined cavity equipped to a hot obstacle using nanofluids considering temperature-dependent properties." International Journal of Heat and Mass Transfer. 85, pp. 656-666. 2015.

https://doi.org/10.1016/j.ijheatmasstransfer.2015.02.009

[10] Hemmat Esfe, M., Saedodin, S., Sina, N., Afrand, M., Rostami, S. "Designing an artificial neural network to predict thermal conductivity and dynamic viscosity of ferromagnetic nanofluid." International Communications in Heat and Mass Transfer. 68, pp. 50-57. 2015. https://doi.org/10.1016/j.icheatmasstransfer.2015.06.013

[11] Bianco, V., Manca, O., Nardini, S. "Second Law Analysis of Al2O3-Water Nanofluid Turbulent Forced Convection in a Circular Cross Section Tube with Constant Wall Temperature." Advances in Mechanical Engineering. 5, Article ID 920278, 2013.

https://doi.org/10.1155/2013/920278
[12] Wang, X., Xu, X., S., Choi, S.U. "Thermal Conductivity of Nanoparticle - Fluid Mixture." Journal of Thermophysics and Heat Transfer. 13, pp. 474-480. 1999. https://doi.org/10.2514/2.6486

[13] Xie, H., Chen, L., Wu, Q. "Measurements of the viscosity of suspensions (nanofluids) containing nanosized $\mathrm{A} 12 \mathrm{O} 3$ particles." High TemperaturesHigh Pressures. 37(2), p. 127-135. 2008.

[14] Hemmat Esfe, M., Saedodin, S. "An experimental investigation and new correlation of viscosity of $\mathrm{ZnO}-\mathrm{EG}$ nanofluid at various temperatures and different solid volume fractions." Experimental Thermal and Fluid Science. 55, pp. 1-5. 2014. https://doi.org/10.1016/j.expthermflusci.2014.02.011

[15] Kang, H. U., Kim, S. H., Oh., J. M. "Estimation of thermal conductivity of nanofluid using experimental effective particle volume." Experimental Heat Transfer. 19, pp. 181-191. 2006.

https://doi.org/10.1080/08916150600619281

[16] Naik, M. T., Janardhana, G. R., Reddy, K. V. K., Reddy, B. S. "Experimental investigation into rheological property of copper oxide nanoparticles suspended in propylene glycol-water based fluids." ARPN Journal of Engineering and Applied Sciences. 5(6), pp. 29-34. 2010.

[17] Namburu, P. K., Kulkarni, D. P., Misra, D., Das, D. K. "Viscosity of copper oxide nanoparticles dispersed in ethylene glycol and water mixture." Experimental Thermal and Fluid Science. 32, pp. 397-402. 2007. https://doi.org/10.1016/j.expthermflusci.2007.05.001

[18] Li, J., Li, Z., Wang, B. "Experimental viscosity measurements for copper oxide nanoparticle suspensions." Tsinghua Science \& Technology. 7(2), pp. 198-201. 2002.

[19] Shoghl, S. N., Bahrami, M. "Experimental investigation on pool boiling heat transfer of $\mathrm{ZnO}$, and $\mathrm{CuO}$ water-based nanofluids and effect of surfactant on heat transfer coefficient." International Communications in Heat and Mass Transfer. 45, pp. 122-129. 2013.

https://doi.org/10.1016/j.icheatmasstransfer.2013.04.015

[20] Saeedinia, M., Akhavan-Behabadi, M. A., Razi, P. "Thermal and rheological characteristics of $\mathrm{CuO}$-Base oil nanofluid flow inside a circular tube." International Communications in Heat and Mass Transfer. 39, pp. 152-159. 2012.

https://doi.org/10.1016/j.icheatmasstransfer.2011.08.001

[21] Menbari, A., Akbar, A., Ghayeb, Y. "Experimental investigation of stability and extinction coefficient of $\mathrm{Al} 2 \mathrm{O} 3-\mathrm{CuO}$ binary nanoparticles dispersed in ethylene glycol - water mixture for low-temperature direct absorption solar collectors." Energy Conversion Management. 108, pp. 501-510. 2015.

https://doi.org/10.1016/j.enconman.2015.11.034

[22] Liu, M., Lin., M. C., Wang. C. "Enhancements of thermal conductivities with $\mathrm{Cu}, \mathrm{CuO}$, and carbon nanotube nanofluids and application of MWNT/water nanofluid on a water chiller system." Nanoscale Research Letter. 6, 297. 2011. https://doi.org/10.1186/1556-276X-6-297

[23] Wang, B. X., Zhou, L. P., Peng, X. F., Du, X. Z., Yang, Y. P. "On the specific heat capacity of $\mathrm{CuO}$ nanofluid." Advances in Mechanical Engineering. 2010, Article ID 172085. 2010. https://doi.org/10.1155/2010/172085

[24] Kwak, K., Kim, C. "Viscosity and thermal conductivity of copper oxide nanofluid dispersed in ethylene glycol." Korea-Australia Rheology Journal. 17, pp. 35-40. 2005.

[25] Masuda, H., Ebata, A., Teramae, K. "Alteration of thermal conductivity and viscosity of liquid by dispersing ultra-fine particles. Dispersion of Al2O3, $\mathrm{SiO} 2$ and $\mathrm{TiO} 2$ ultra-fine particles." 1993. https://doi.org/10.2963/jitp.7.227 
[26] Duangthongsuk, W., Wongwises, S. "Measurement of temperature-dependent thermal conductivity and viscosity of TiO 2-water nanofluids." Experimental Thermal and Fluid Science. 33, pp. 706-14. 2009. https://doi.org/10.1016/j.expthermflusci.2009.01.005

[27] Lee, S. W., Park, S. D., Kang, S., Bang, I. C., Kim, J. H. "Investigation of viscosity and thermal conductivity of SiC nanofluids for heat transfer applications." International Journal of Heat and Mass Transfer. 54, pp. pp. 433-438. 2011.

https://doi.org/10.1016/j.ijheatmasstransfer.2010.09.026

[28] Pastoriza-Gallego, M. J., Lugo, L., Legido, J. L., Piñeiro, M. M. "Thermal conductivity and viscosity measurements of ethylene glycol-based A12O3 nanofluids." Nanoscale Research Letters. 6, pp. 1-11. 2011. https://doi.org/10.1186/1556-276X-6-221

[29] Pastoriza-Gallego, M. J., Lugo, L., Cabaleiro, D., Legido, J. L., Piñeiro, M. M. "Thermophysical profile of ethylene glycol-based $\mathrm{ZnO}$ nanofluids." Journal of Chemical Thermodynamics. 73, pp. 23-30. 2014. https://doi.org/10.1016/j.jct.2013.07.002

[30] Żyła, G. "Thermophysical properties of ethylene glycol based yttrium aluminum garnet (Y 3 Al 5 O 12-EG) nanofluids." International Journal of Heat and Mass Transfer. 92, pp. 751-756. 2016. https://doi.org/10.1016/j.ijheatmasstransfer.2015.09.045

[31] Mariano, A., Pastoriza-Gallego, M. J., Lugo, L., Mussari, L., Piñeiro, M. M. "Co3O4 ethylene glycol-based nanofluids: thermal conductivity, viscosity and high pressure density." International Journal of Heat and Mass Transfer. 85, pp. 54-60. 2015. https://doi.org/10.1016/j.ijheatmasstransfer.2015.01.061

[32] Żyła, G., Fal, J., Gizowska, M., Witek, A., Cholewa, M. "Dynamic Viscosity of Aluminum Oxide-Ethylene Glycol (A12O3-EG) Nanofluids." Acta Physica Polonica A. 128, p. 2. 2015.

[33] Żyła, G., Fal, J. "Experimental studies on viscosity, thermal and electrical conductivity of aluminum nitride-ethylene glycol (AlN-EG) nanofluids." Thermochimica Acta. 637, pp. 11-16. 2016. https://doi.org/10.1016/j.tca.2016.05.006

[34] Mariano, A., Pastoriza-Gallego, M. J., Lugo, L., Camacho, A., Canzonieri, S., Piñeiro, M. M. "Thermal conductivity, rheological behaviour and density of non-Newtonian ethylene glycol-based SnO 2 nanofluids." Fluid Phase Equilibria. 337, pp. 119-124. 2013. https://doi.org/10.1016/j.fluid.2012.09.029
[35] Li, X., Zou, C., Wang, T., Lei, X. "Rheological behavior of ethylene glycol-based SiC nanofluids." International Journal of Heat and Mass Transfer. 84, pp. 925-930. 2015.

https://doi.org/10.1016/j.ijheatmasstransfer.2015.01.104

[36] Nguyen., C. T., Desgranges, F., Galanis, N., Roy, G., Maré, T., Boucher, S., Angue Mintsa, H. "Viscosity data for Al 2 O 3-water nanofluid-hysteresis: is heat transfer enhancement using nanofluids reliable?." International Journal of Thermal Sciences. 47, pp. 103-111. 2008. https://doi.org/10.1016/j.ijthermalsci.2007.01.033

[37] Jamshidi, N., Farhadi, M., Ganji, D. D., Sedighi, K. "Experimental investigation on viscosity of nanofluids." International Journal of Engineering. 25, pp. 201-209. 2012. https://doi.org/10.5829/idosi.ije.2012.25.03b.07

[38] Kulkarni, D. P., Das, D. K., Chukwu, G. A. "Temperature dependent rheological property of copper oxide nanoparticles suspension (nanofluid)." Journal of Nanoscience and Nanotechnology. 6, pp. 1150-1154. 2006. https://doi.org/10.1166/jnn.2006.187

[39] Masoumi, N., Sohrabi, N., Behzadmehr, A. "A new model for calculating the effective viscosity of nanofluids." Journal of Physics D: Applied Physics. 42, 055501. 2009. https://doi.org/10.1088/0022-3727/42/5/055501

[40] Singh, R., Sanchez, O., Ghosh, S., Kadimcherla, N., Sen, S., Balasubramanian, G. "Viscosity of magnetite-toluene nanofluids: Dependence on temperature and nanoparticle concentration." Physics Letters A. 379(40-41), pp. 2641-2644. 2015.

https://doi.org/10.1016/j.physleta.2015.06.010

[41] Einstein, A. "Eine neue bestimmung der moleküldimensionen." Annalen der of Physik. 324(2), pp. 289-306. 1906. (in German) https://doi.org/10.1002/andp.19063240204

[42] Batchelor, G. K. "The effect of Brownian motion on the bulk stress in a suspension of spherical particles." Journal of Fluid Mechanics. 83(1), pp. 97-117. 1977. https://doi.org/10.1017/S0022112077001062

[43] Rostamian, H., Lotfollahi, M. N. "New Functionality for Energy Parameter of Redlich-Kwong Equation of State for Density Calculation of Pure Carbon Dioxide and Ethane in Liquid, Vapor and Supercritical Phases." Periodica Polytechnica Chemical Engineering. (60)2, pp. 93-97. 2016. https://doi.org/10.3311/PPch.8221 